Uluslararası Mühendislik

Cilt/Volume:11 Sayı/Issue:2 Haziran/June 2019

Araştırma Makalesi / Research Article

\title{
Nokta Bulutu Verileri Kullanarak Tarihi Edirne Mihalbey Hamamı'nın Farklı Modellerle İrdelenmesi
}

\section{Examine of Historical Edirne Mihalbey Public Bath With Different Models By Using Point Cloud Data}

\author{
Yusuf Demirel $^{1}$ iD, Fatih Aydoğmuş $^{1}$ i \\ ${ }^{l}$ Gazi Üniversitesi Mühendislik Fakültesi İnşaat Mühendisliği Bölümü, O6570 Ankara, TÜRKIYE
}

Başvuru/Received: $30 / 04 / 2019$

Kabul/Accepted: $31 / 05 / 2019$

Son Versiyon/Final Version: 30/06/2019

\section{Öz}

Bu çalışmada Edirne ilinde bulunan 15. Yüzyıl yapılarından Mihalbey hamamın mevcut durumunu irdelemesinde iki farklı model kullanılması amaçlanmıştır. Klasik ve voksel modelleme yöntemi altında sayısal analizi yapılmıştır. Bu amaçla klasik modellemede; nokta bulutu verileri üzerinden rölöve ve klasik taşıyıcı sistem oluşturulmuştur. Ölü yükler sisteme etkitilmiştir. Voksel modellemede ise rölöveye ihtiyaç duyulmadan, nokta bulutu verileri dâhilinde tüm yapı ve ölü yükler küp eleman olarak tanımlanmış ve davranışa dâhil edilmiştir.

Klasik modelleme ile voksel modelleme yöntemi SAP2000 programı ile analiz edilmiştir. Analiz öncesi, analiz aşaması ve analiz sonrası verileri değerlendirilmiştir.

Voksel modele ait analiz sonuçları, klasik modelleme tekniği kullanılarak elde edilen değerlerle karşılaştırılmış ve iki modelleme sisteminin avantaj ve dezavantajları değerlendirilmiştir.

\section{Anahtar Kelimeler}

"Tarihi yapılar, Nokta Bulutu, Voksel Modelleme, Sismik Davranış, Edirne Mihalbey Hamamı"

\begin{abstract}
This study employs two different models to examine the present status of the 15th century Mihalbey Public Bath in Edirne. Numerical analysis was performed using classical and voxel modeling methods. For this purpose, in classical modeling; the survey and point cloud data were used to build a structural system. Dead loads were added to the system. In the voxel modeling, all structure and dead loads were defined as cube elements without the need for a survey.

Classical modeling and voxel modeling were analyzed in SAP2000 program. Before the analysis, the analysis phase and postanalysis data were evaluated.

Analysis results of the voxel model, classical modeling technique was compared with the obtained values and the advantages and disadvantages of two models were evaluated.
\end{abstract}

Key Words

"Historical buildings, Point Cloud, Voxel Modeling, Seismic Behavior, Edirne Mihalbey Turkish Bath" 


\section{Giriş}

Tarihi yapılarda çekme ve eğilme taşıyan yapı elemanı bulunmamaktadır. Bunun nedeni çekme kuvvetini alan donatının ve bağlayıcı malzemelerin (beton gibi) bulunmamasıdır. Tarihi yapıların taşıyıcı sisteminin modellenmesi oldukça zor ve titiz bir çalışma gerektirmektedir. Bu tür taşıyıcı sisteme sahip yapıların hem yapısal hem de eleman bazında davranışını yorumlayabilmek günümüz mühendisleri için oldukça zordur. Bunun nedeni, günümüz yapılarında betonarme ve çelik yapıların etkin olması ve mühendislik eğitiminde basınç etkin yığma yapılar üzerinde yeterince durulmamasıdır. Bu durum, mevcut tarihi yapıların değerlendirilmesinde farklı sonuçların ve değerlendirmelerin çıkmasına neden olmaktadır.

Nokta bulutu saha ölçümlerinde kullanılan lazer tarayıcıyla elde edilen üç boyutlu koordinatlı nokta kümesidir. TLS (Terrestrial laser scanner- Karasal lazer tarayıcı) kısa adıyla anılan bu cihazlar optik bir cihazlardır.

Gönderilen lazer ışınların yüzeylerden yansımasıyla yöneltilen yüzeye ait gerçek zamanlı nokta kümeleri oluşturmaktadır. Prensip olarak lazer ışınlarının yatay ve düşey doğrultularda 360 derece tarayacak şekilde gönderilmesiyle ölçülen mesafe ve açı değerleri anlık olarak kodlanarak elde edilen polar koordinatlar $(\mathrm{r}, \theta, \beta)$, kartezyen koordinatlara $(\mathrm{x}, \mathrm{y}, \mathrm{z})$ dönüştürülmektedir. Tarihi yapılarda, iç ve dış mekânların birçok noktasından elde edilen nokta bulutlarının birleştirilmesi sonucu mevcut yapının iç ve dış koordinat sistemleri detaylı olarak elde edilebilmektedir. Nokta bulutu verilerinden yapısal model oluşturmak için geçerli olan iki modelleme tekniği mevcuttur. Bu yöntemeler; ağ oluşturma (mesh generation) yöntemi ve Voksel (voxelization) yöntemleridir.

Ağ oluşturma yönteminde; nokta bulutunda oluşturulan koordinat verileri veya yüksek çözünürlüklü fotoğraflar derlenerek yapının yüzey geometrisi oluşturulur. Bu aşamada gereksiz nokta koordinatları ayıklanır. Oluşturulan ağ sistemi, rölöveye dönüştürülür ve mühendislik önsezisi ile tahmin edilen yapı taşıyıcı sitemi dâhilinde eleman ve kesit boyutu tanımlanır. Bu yapı taşıyıcı sitemi sonlu elamanlar programlarına yönlendirilerek tarihi yapı analiz edilmeye çalışılır (Alicandro, 2017) (Castellazzi, ve diğerleri, 2016) (Cardani \& Angjeliu, 2016) (Manich, ve diğerleri, 2016). Bu tip modellemelere klasik modelleme adı verilebilir.

Veri alınımı ve bilgisayar kapasitesinin artması sonucu farklı modelleme tekniklerinin klasik modellemenin yerini alması doğaldır. Voksel modelleme tekniği bunlardan biridir. Voksel; bir pikselin üç boyutlu karşılığıdır. Piksel, bir noktayı iki boyutlu olarak tanımlarken voksel bir noktayı üç boyutlu uzayda tanımlayan grafik bilgisini ifade etmektedir (Giordano, Mele, \& De Luca, 2002) (Castellazzi, D'Altri, Miranda, \& Ubertini, 2016) (Roca, Cervera, Gariup, \& Pela, 2010) (Castellazzi, D’Altri, Bitelli, Selvaggi, \& Lambertini , 2015)

\section{Yapısal Modellemeler ve Analiz Sonuçlarının Tartışılması}

Klasik ve voksel modellemelere referans olan Tarihi Edirne Mihalbey Hamam'1, Tunca nehri üzerindeki Gāzi Mihâl Bey köprüsünün kuzeydoğu köşesinde yer almakta olup Şahmelek Câmi'nin karşısındadır. Tarihi kayıtlar incelendiğinde hamamın 15. Yüzyılın ilk çeyreğinde inşa ettirildiğini tahmin edilmektedir (Asır Proje Arşivi, 2017). Dıştan dışa 22,70x23,20 metre ebadındaki eser, doğu-batı doğrultusunda uzanan dikdörtgene yakın bir plana sahiptir (Şekil 1,Şekil 2).

a

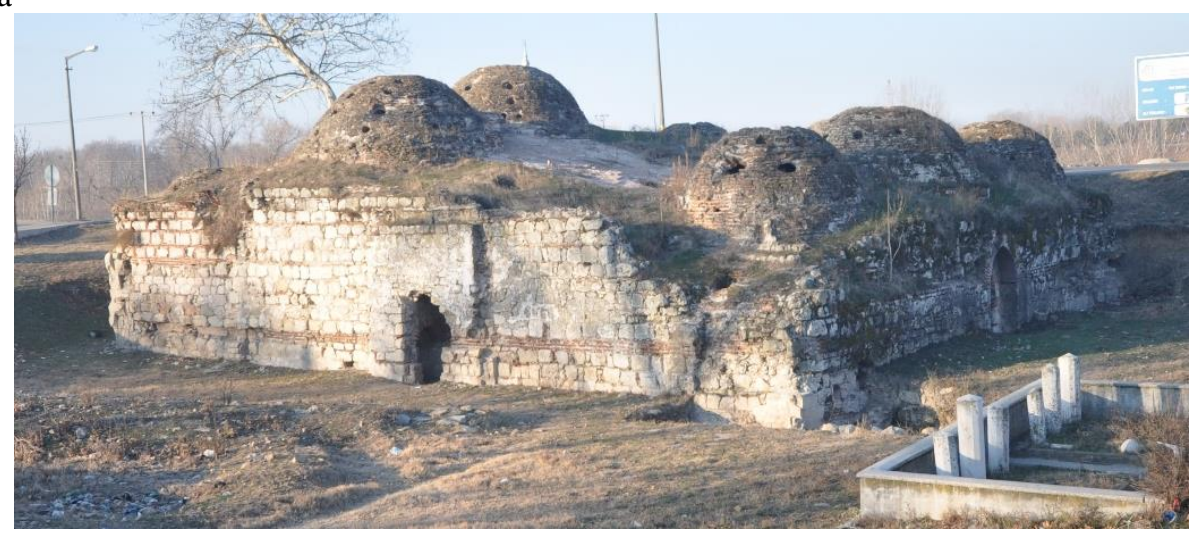

b

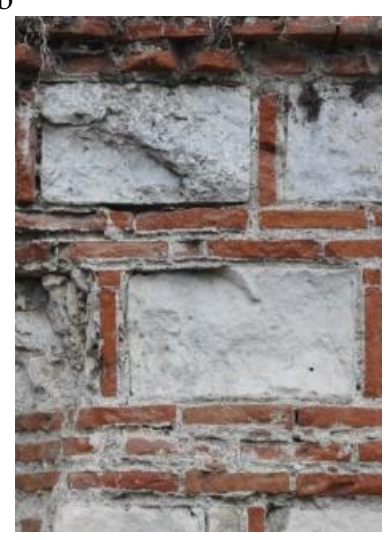

Şekil 1. (a) Hamam genel görünüm; (b) Duvar örgüsü

Kâgir malzemeden yığma tekniğinde inşâ edilen yapıda (Şekil 1a); kesme yonu moloz taş, tuğla, mermer, alçı, kireç harcı kullanılmıştır. Yapının beden duvarları; kesme, yontu ve moloz taş sırası arasına ikişer-üçer sıra şeklinde tuğla hatılların atıldığı almaşık duvar tekniğinde oluşturulmuştur (Şekil 1b). Cephelerde tuğla hatıllar arasında kalan yontu ve kesme taşlar, her biri arasına birer dikey tuğla ile kasetlenerek mozaik görüntüsü oluşturmuştur. Beden duvarlarında kullanılan malzeme ve teknik, aynı şekilde kubbelerin poligonal formlu kasnaklarında da tekrarlandığı görülmektedir. Yapının kâgir malzemeli duvar örgüsünde, üst örtüde ve zemin döşemesinde birleştirici unsur olarak kireç harcın kullanıldı̆̆ı görülmektedir. 


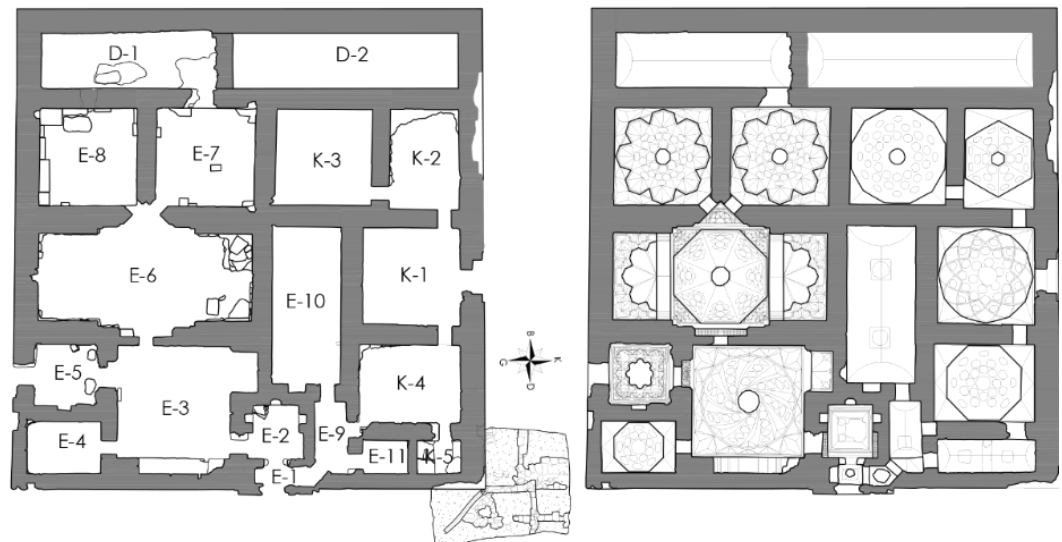

Şekil 2. Hamam mekanları iz düşüm planı ve tavan planı

Yapının tüm bölümleri için kullanılan tüm yapı malzemelerinin mekanik değerlerinin bilinmesi neredeyse imkânsızdır. Diğer taraftan bilgisayar modelinin karmaşıklığı arttıkça verilerin doğru bir şekilde girilmesi ve analiz sonuçlarının değerlendirilmesi de zorlaşmaktadır. Bu zorluklardan ötürü yeterli malzeme deneyinin yapılabildiği küçük ölçekli yapılar dışında duvar yapısını homojen izotropik bir model olarak hesaba alan makro modelleme tekniği daha uygun bir çözüm olarak görülmektedir (Giordano, Mele, \& De Luca, 2002).

Hamam yapısının geometrisinin belirlenmesi için içeriden ve dışarıdan toplamda 67 farklı noktada lazer ölçümü yapılmıştır. Lazer tarayıcının 360 derece tarama verileri alınmış, modelleme aşamasında gerekli olmayacak noktalar buluttan silinerek, modelleme için gerekli nokta bulutu ortaya çıkarılmıştır. Elde edilen yapının 20 milyon noktadan oluşan nokta bulutu görüntüsü Şekil 3'de verilmiştir.

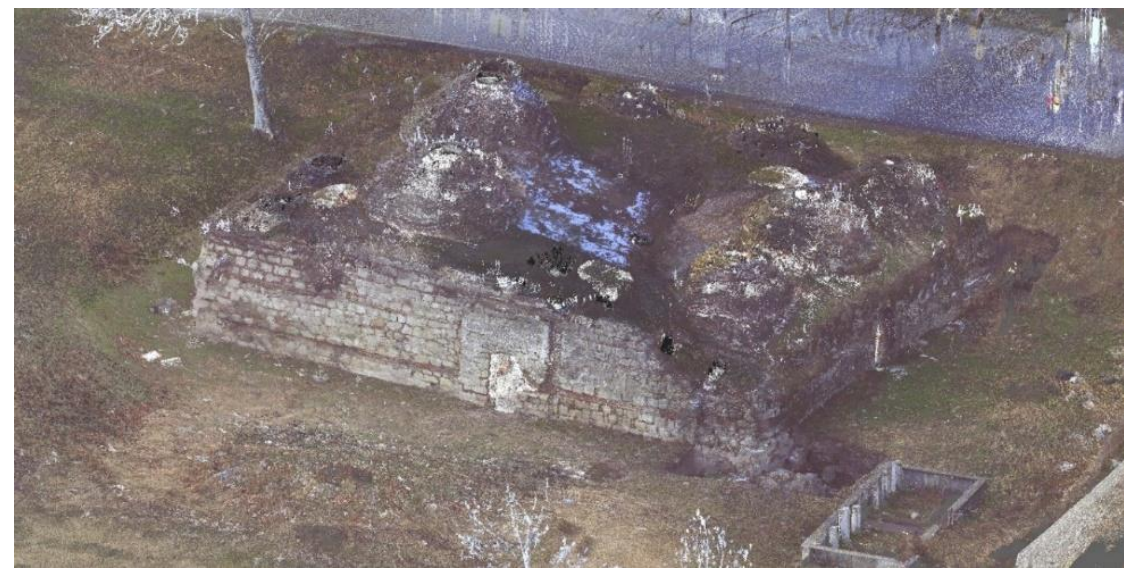

Şekil 3. 20 milyon noktadan oluşmuş nokta bulutu görüntüsü

Çalışmada, makro modelleme tekniği kullanılarak iki farklı yöntemle analiz modeli oluşturulmuştur. Analizlerde kullanılan malzemelere ait değerler Tablo 1'de verilmiştir (Magenes \& Penna, 2009).

Tablo 1: Kullanılan malzemeler

\begin{tabular}{lccc}
\hline Eleman Türü & Birim Hacim Ă̆ırlık (kN/m $\left.{ }^{3}\right)$ & Elastisite Modülü (MPa) & Basınç dayanımı (MPa) \\
\hline Kubbeler & 18 & 1900 & 1.8 \\
\hline Taş Kemerler & 21 & 1600 & 1.5 \\
\hline Duvarlar & 21 & 1750 & 1.6
\end{tabular}

Klasik analiz modelinde nokta bulutundan elde edilen rölöveden yapı geometrisi ve kalınlıklar, mühendislik (bu analizde biz) tecrübeleri dâhilinde değerlendirilerek yapı taşıyıcı sistemi elemanları taşıyıcı duvar, kemer, kubbe, tonozlar oluşturulmuştur. Bu modelde kubbe ve pandantif elemanlar için kabuk (Shell) kullanılırken, yapı duvarlar için katı (solid) elemanlar kullanılmıştır. Ayrıca yüklemeler ve yükler yine tecrübe ve bilgi dâhilinde belirlenerek modele etki edilmiştir.

Nokta bulutu verilerinden görüntülenebilen iç ve diş kabuk geometrilerinden hareketle; kubbe, tonoz, kemer, geçiş elemanları (pandantifler) ve duvar kesitlerinin merkezleri tespit edilerek üç boyutlu yapı taşıyıcı sistem iskeleti oluşturulmuştur. Oluşturulan iskelet Sap2000 programına aktarılarak kabuk, çubuk veya katı geometriye sahip yapı elemanlarının modellenmesi sağlanmıştır. Nokta bulutu verilerinin yapının gerçek geometrisine yakın modellemede oldukça etkili bir veri olduğu söylenebilir. Şekil 4a'da iç mekân ölçümlerinden oluşan yapı nokta bulutu görüntüsü, Şekil 4b'de ise Sap 2000'ne girilen yapı elemanları ve görüntüleri verilmektedir. 

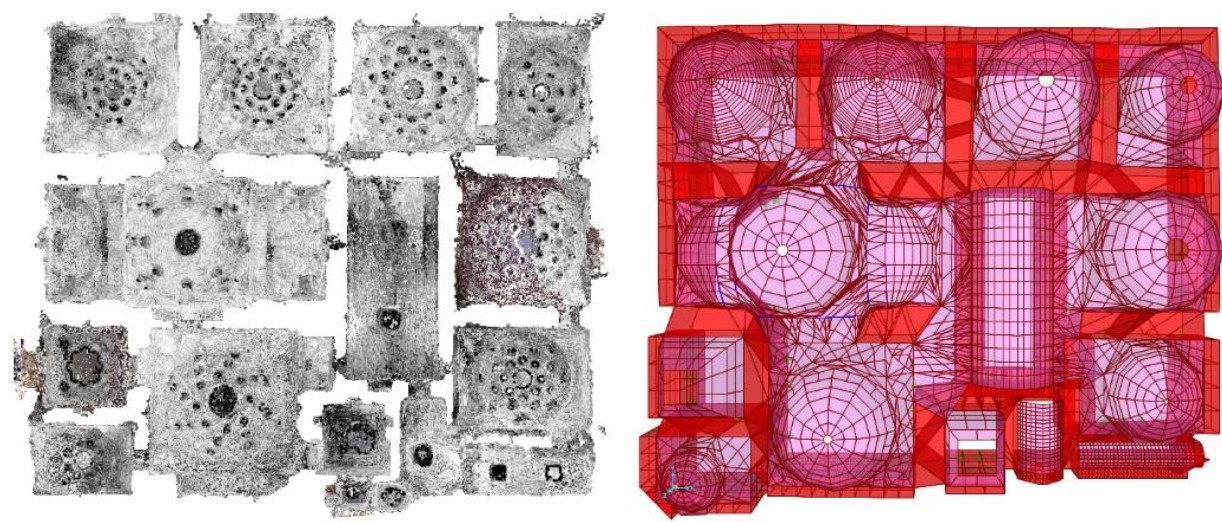

Şekil 4. (a) Nokta Bulutu üst görünüş, (b) Sap2000 modeli üst görünüş

Yapıyı oluşturan duvarlar Sap2000 modeli için idealize edilerek faklı kalınlıkları göz önüne alınmıştır. Bu sebeple beden duvarları 75-120 cm arası, tuğla kubbelerde 33-47 cm arası, ara duvarlarda ise en kalını $150 \mathrm{~cm}$, en incesi $45 \mathrm{~cm}$ olmak dokuz farklı kalınlık kullanılmıştır. Duvarlar katı (solid) eleman, kubbeler ve pandantifler düzlem (Shell) eleman ve kemerler çubuk (frame) eleman olarak tanımlanmıştır. Yapı modeli 3d ve alt görünüşü Şekil 5a ve Şekil 5b'de verilmiştir. Bu modellemede 94 çubuk, 2443 plak ve 483 katı eleman olmak üzere toplam 3020 elemandan oluşan yapı sistemi kullanılmıştır.
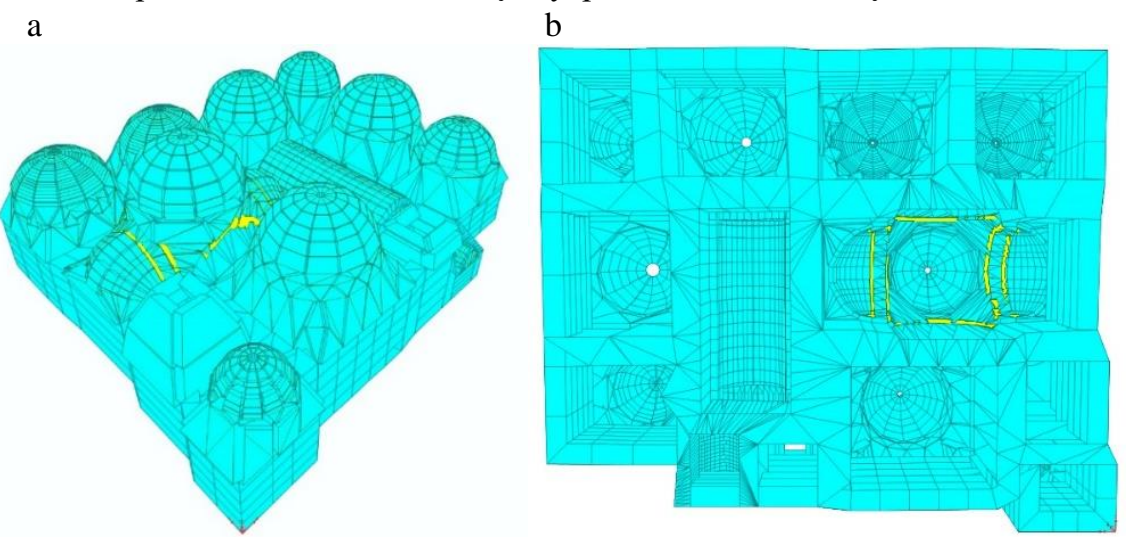

Şekil 5. (a) Sap modeli 3d görünüş (b)Sap modeli alt görünüş

İkinci modelleme tekniği olarak kullanılan voksel modellemesinde ise sadece nokta bulutu verileri kullanılarak yap1 geometrisi oluşturulmuştur. Küp formunda yapı elemanlarından yapı taşıyıcı sistemi ve düşey yükleri oluşturulabilmektedir. Bu çalıșmada $25 \times 25 \times 25 \mathrm{~cm}^{3}$ hacimli katı (solid) elemanlarla modelleme yapılmıştır. Toplamı yapı yüksekliğine tekabül edecek, plan düzleminde $25 \mathrm{~cm}$. 'lik 35 adet katmandan oluşan yapı voksel modeli elde edilmiştir (Şekil 6a-b). Bu modelleme için toplamda 63144 küp eleman kullanılmıştır.

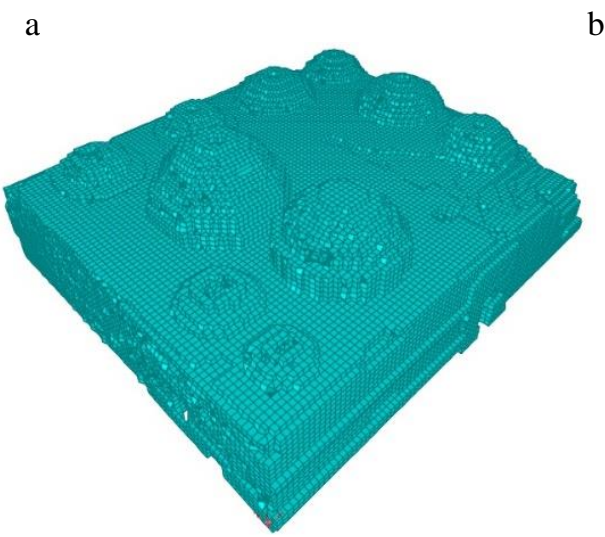

Şekil 6. (a) Voksel Sap modeli 3d görünüş

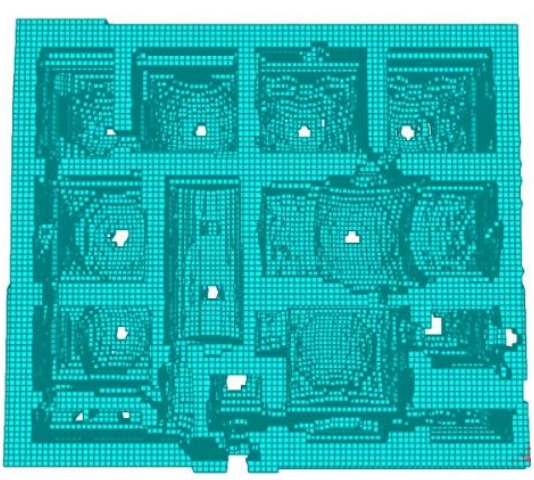

(b) Voksel Sap modeli alt görünüş

Voksel modelde ait birim küp boyutları tüm analiz için veya bölgesel olarak değiştirilebilir. Şekil 7`de voksel modele ait üç boyutlu görünüş verilmektedir. Hamam yapısının modelleme detaylarını göstermek amacıyla hamamın voksel modellemesindeki görünüşüne benzer açıdan çekilmiş fotoğrafı Şekil 8'de verilmiştir. Ancak yapı üzerindeki zamanla oluşan dolgunun ölü yüklemesi voksel modelinde gösterilmemiştir. 


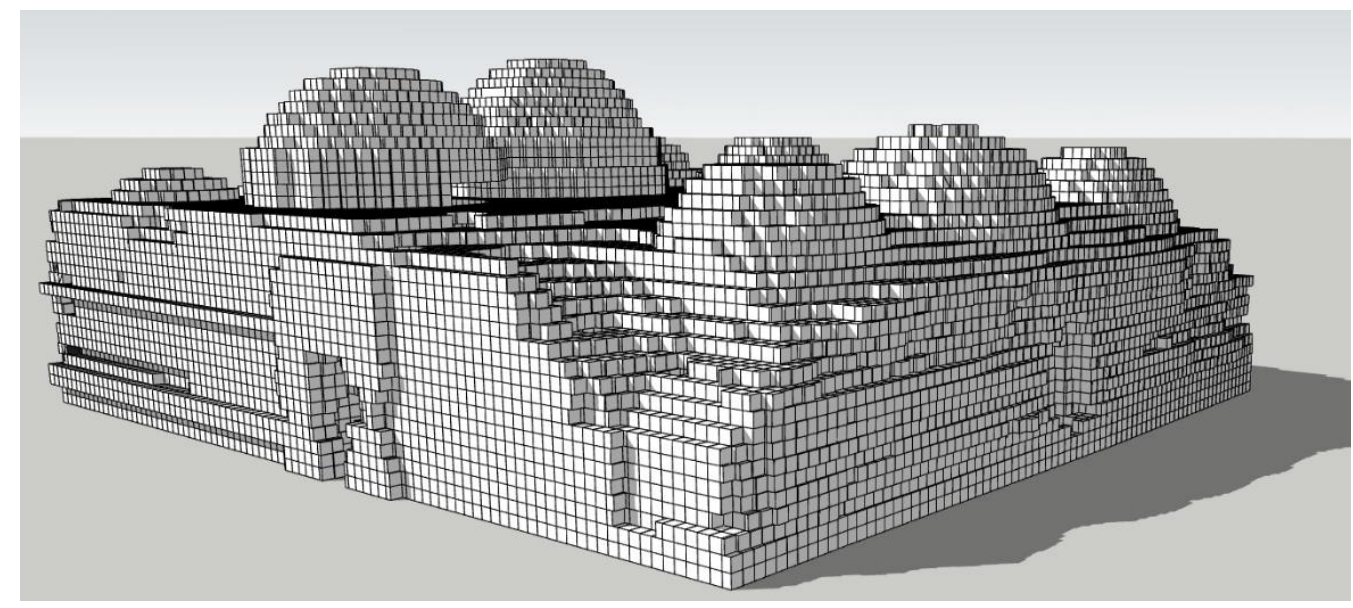

Şekil 7. Voksel model üç boyutlu görünüş

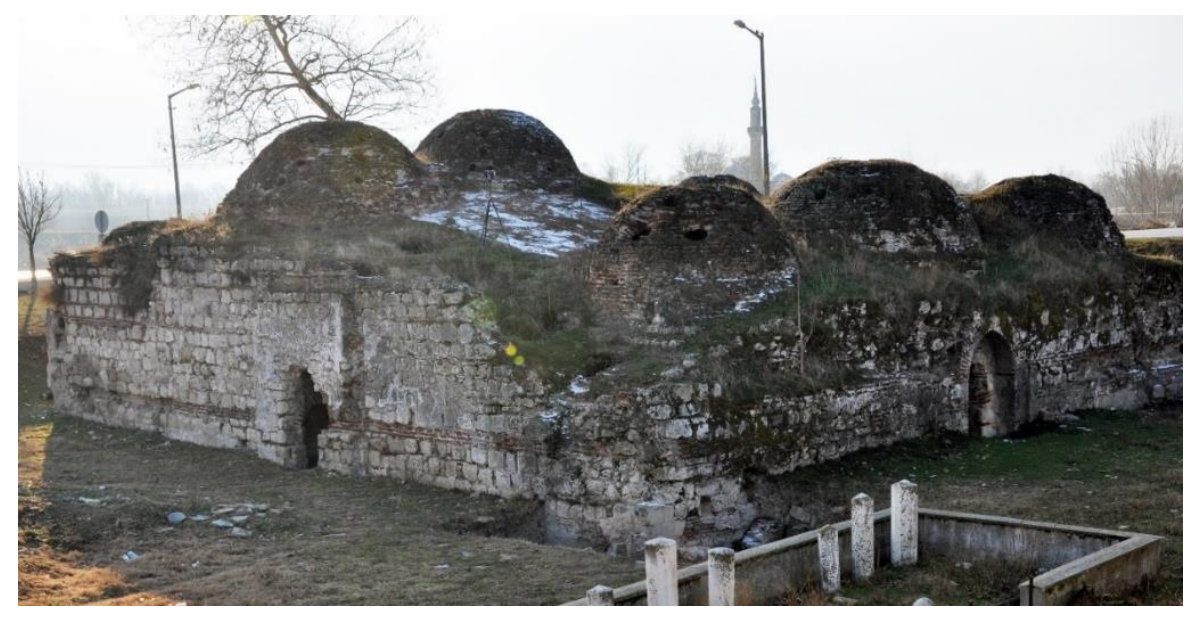

Şekil 8. Mihalbey hamamı kuzeydoğu köşesi görünüş

İçeriden ve dışarıdan olmak üzere 67 noktadan alınan nokta bulutu verilerinin rölöve çalışmasına gereksinin duyulmadan voksel modelde değerlendirilmesi sonucu yapının iç ve dış kısımlarını gösteren A-A düşey kesit Şekil 9 ve B-B yatay kesit Şekil 10‘da verilmiş̧ir. Bu modelleme sayesine yapıda çubuk eleman, plak veya katı eleman tanımlaması yapılmadan tüm yapı davranışa dâhil edilmiştir.

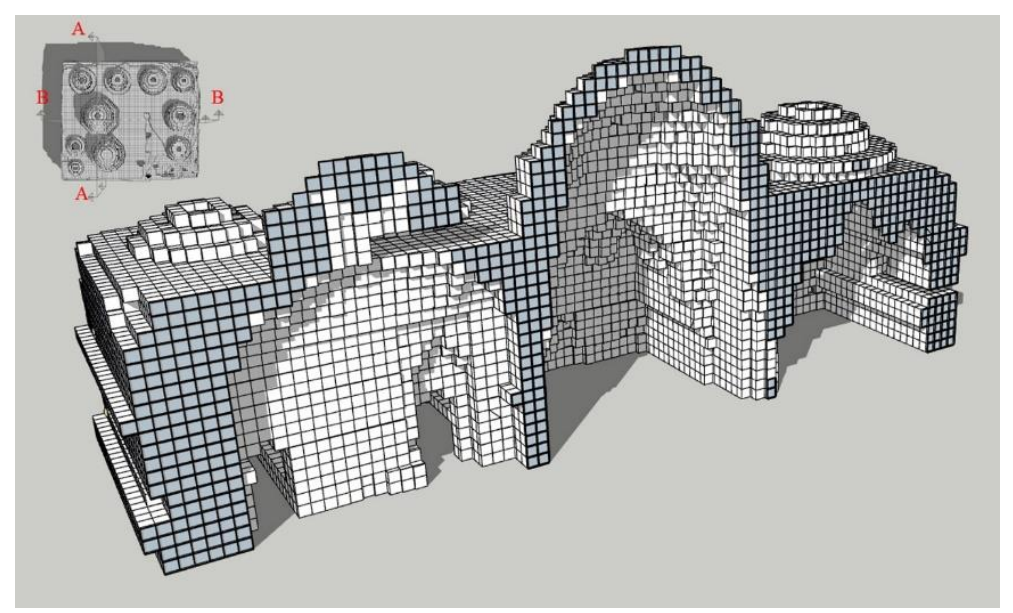

Şekil 9. Voksel model A-A kesiti perspektif görünüş 


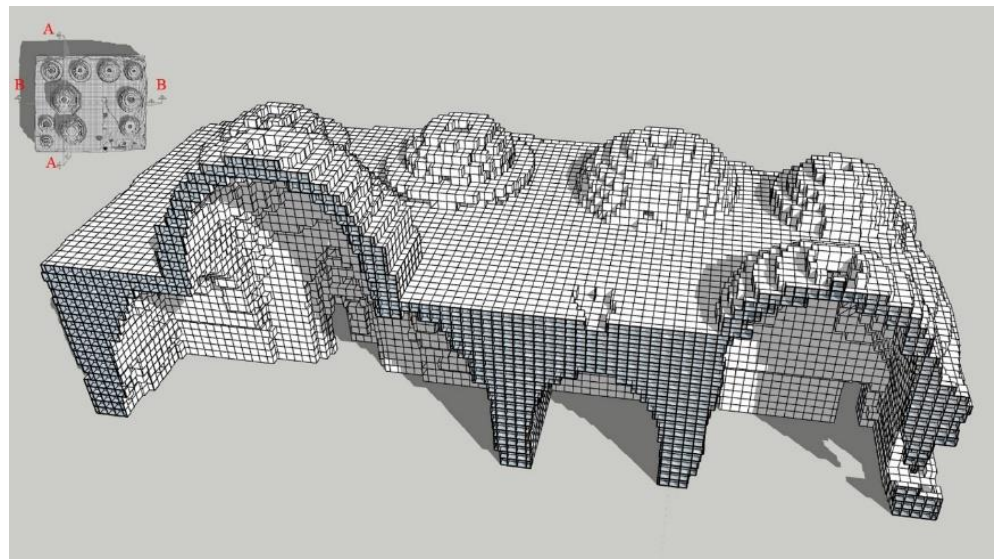

Şekil 10. Voksel model B-B kesiti perspektif görünüş

Yapının her iki yöntemle analizi için; Edirne depremselliği ve yapının bulunduğu zemin koşulları göz önüne alınmıştır. Yapıda zemin ve deprem parametreleri olarak maksimum yer ivmesi $0,10 \mathrm{~g}$ ve k1sa periyot $0,20 \mathrm{sn}$. uzun periyot $0,90 \mathrm{sn}$. olmak üzere zemin sınıfı Z4 zemin için değerler kullanılmıştır.

Her iki model için, deprem yükleri belirlenirken bina önem katsayısı I=1,0 olarak alınmıştır. Deprem analizleri için spektrum katsayısı yı̆̆ma yapılar için önerildiği üzere 2,5 olarak kabul edilmiştir(DBYBHY, 2007).Spektrum değerleri 4.derece deprem bölgesi ve Z4 zemin sınıfı için tanımlanmıştır. Sistemde ölü yüklerin ve yapı elemanların zati ağırlıklarını dikkate alınmıştır. Bu ölü yük, üst döşemedeki $80 \mathrm{~cm}$ kalınlığında dolgunun yükünü ifade etmektedir. Plak ve çubuk elemanlarla oluşturulan klasik modelde, dolgu yükleri sisteme $1,25 \mathrm{t} / \mathrm{m}^{2}$ olarak etkitilmiştir. Voksel modelde ise dolgu alanı ve yoğunluğu tanımlandığı için buna ihtiyaç duyulmamıştır. Taşıyıcı sistem davranış katsayısı $\mathrm{R}=2$ olarak dikkate alınmıştır. Yapısal analizlerde mod birleştirme yöntemi kullanılmıştır.

Her iki modellemede de kayma gerilmeleri 0,10 MPa olarak alınmıştır. Duvar kayma dayanımını $(\tau)$ bulmak için başlangıç kayma dayanımına duvara etkiyen normal gerilmenin $(\sigma)$ katkısı eklenmektedir, Oluşan eksenel gerilme değeri $0.15 \mathrm{MPa}$ mertebesindedir. Duvar kayma dayanımı; $\tau=\tau_{0}+0,4 \sigma$ ise $\tau=0,10+0,4 \times 0,15=0,16 \mathrm{MPa}$ 'dır. Yapılan hesaplamalarda yapı ağırlığ klasik analiz modeli için 2130,0 ton, voksel modeli için ise 1902,5 ton olarak bulunmuştur. İlk üç mod için toplam ötelenmeler, Klasik model ve voksel model için görsel karşılaştırma amacıyla aşağıda verilmiştir.

Mod 1'de klasik model yap1 periyodu 0,086 sn.ve voksel model yap1 periyodu 1,623 sn.dir. Klasik model yap1 periyodu voksel modele göre \%94 daha kısadır. Klasik model mod 1 için belirleyici unsur E3 kubbesi ile K2, K1, K4 bölümlerine ait üst örtü ve duvarlar olurken voksel modelde yapının $\mathrm{X}$ yönünde tüm kütlesinin 1. moda etkin olduğu görülmüştür. Klasik modelde maksimum toplam yer değiştirme $39 \mathrm{~mm}$. iken voksel modelde maksimum yer değiştirme $4 \mathrm{~mm}$. olarak bulunmuştur. Klasik modelde yer değiştirmelerin voksel modele oranla 9-10 kat daha fazla oluşmasının sebebi de toplam yer değiştirmenin E3 kubbesi üzerinde hesaplanmasından kaynaklanmaktadır. Mod 1 için voksel model beklenen yapı davranışına daha yakın sonuçlar vermiştir (Şekil $11)$.

a

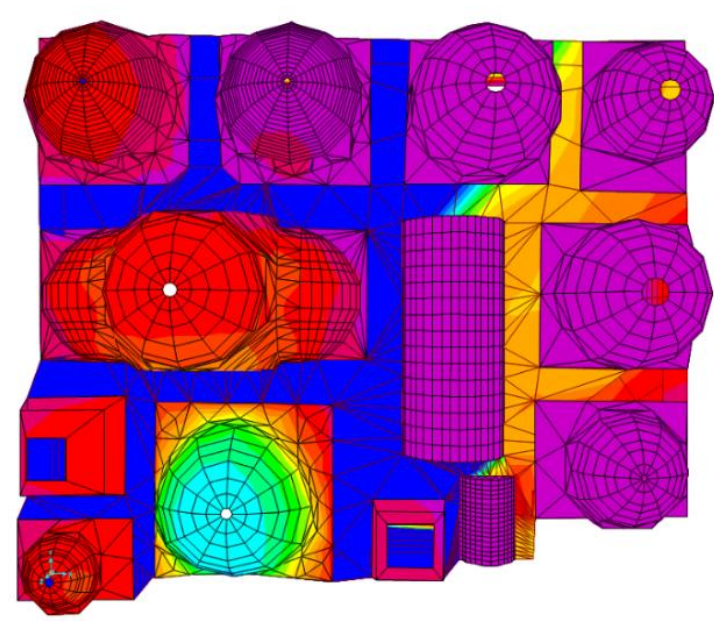

$\mathrm{b}$

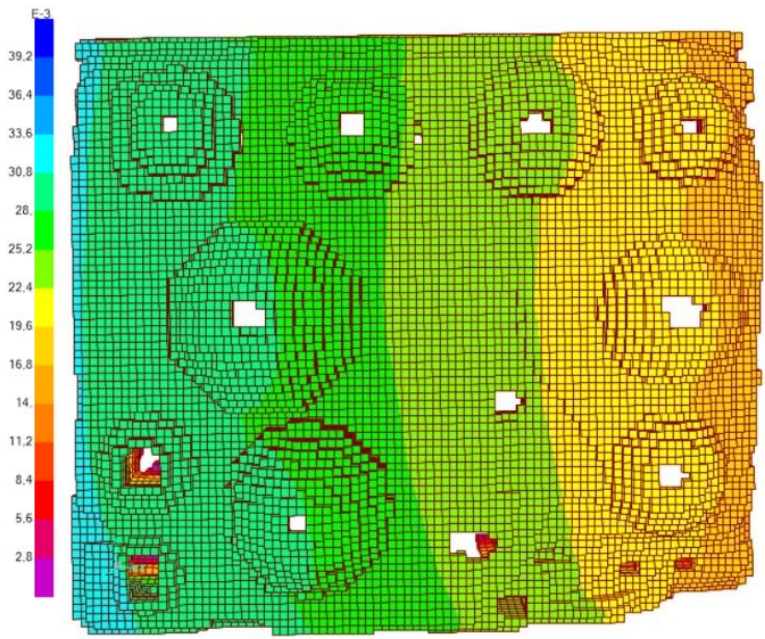

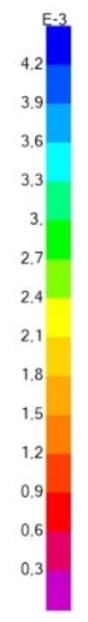

Şekil 11. (a) Klasik model 1.mod (min. 0 m /maks.0.039m) (b)Voksel model 1.mod (min. 0 m / maks.0.004 m)

Mod 2'de klasik model yap1 periyodu 0,081 sn.ve voksel model yap1 periyodu 1,507 sn.dir. Klasik model yapı periyodu voksel model yapı periyoduna göre \%94 daha kısadır. Klasik model 2. modu için belirleyici unsur E8 kubbesi ile K1, K4 ait üst örtü ve duvarları olurken voksel modelde yapının Y yönünde tüm kütlesinin 2. moda etkin olduğu görülmüştür. Klasik modelde maksimum toplam yer değiştirme $40 \mathrm{~mm}$. iken voksel modelde maksimum yer değiştirme $3 \mathrm{~mm}$. olarak bulunmuştur. Klasik modelde yer 
değiştirmelerin, voksel modele oranla 13 kat daha fazla oluşmasının sebebi de toplam yer değiştirmenin E8 kubbesi üzerinde hesaplanmasından kaynaklanmaktadır. Mod 2 için voksel beklenen yapı davranışına daha yakın sonuçlar vermiştir (Şekil 12).

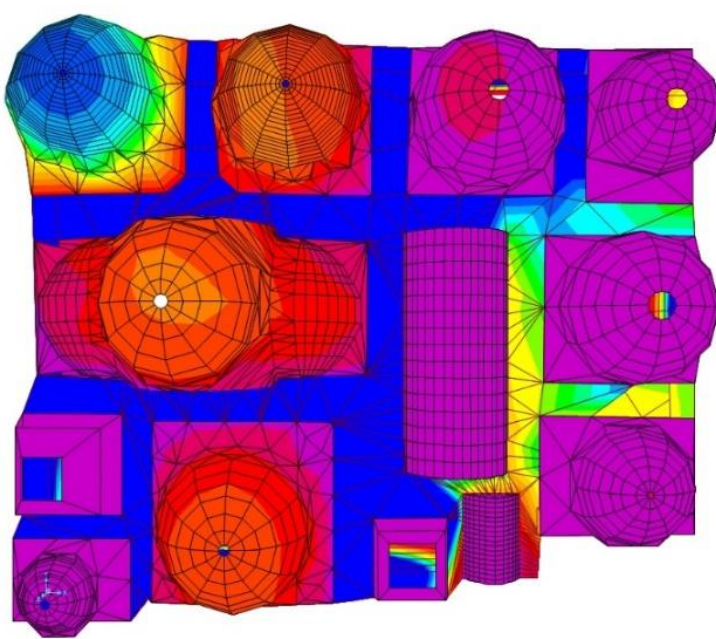

b

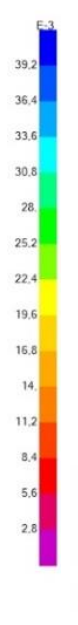

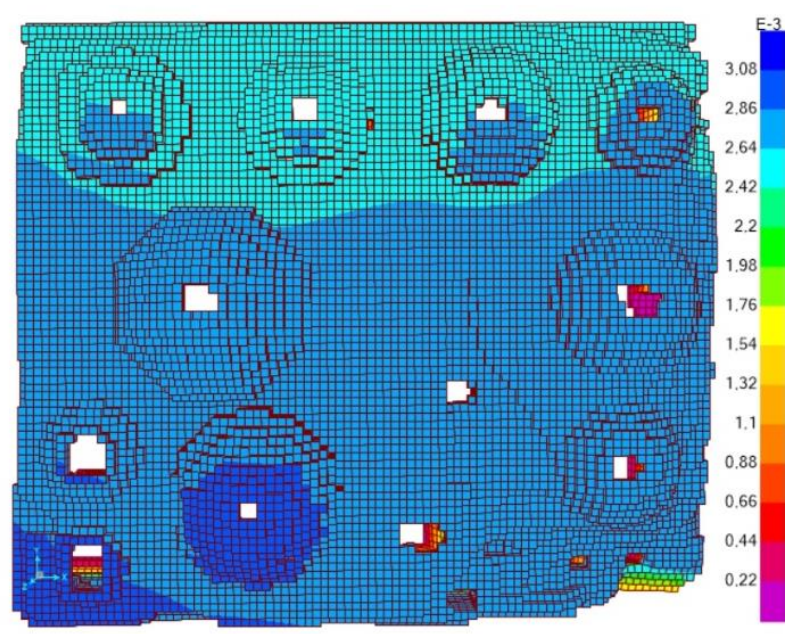

Şekil 12. (a) Klasik model 2.mod (min. $0 \mathrm{~m} / \mathrm{maks.0.04} \mathrm{m)} \mathrm{(b)Voksel} \mathrm{model} \mathrm{2.mod} \mathrm{(min.} 0 \mathrm{~m} / \mathrm{maks} .0 .003 \mathrm{~m})$

Mod 3'de klasik model yap1 periyodu 0,078 sn.ve voksel model yap1 periyodu 1,297 sn.dir. Klasik model yapı periyodu voksel model yapı periyoduna göre \%94 daha kısadır. Klasik model mod 3 için belirleyici unsur K2 olurken, voksel modelde yapının Z yönünde tüm kütlesinin 1. moda etkin olduğu görülmüştür. Klasik modelde maksimum toplam yer değiştirme $31 \mathrm{~mm}$. iken voksel modelde maksimum yer değiştirme $5 \mathrm{~mm}$. olarak bulunmuştur. Klasik modelde yer değiştirmelerin voksel modele oranla 6 kat daha fazla oluşmasının sebebi de toplam yer değiştirmenin K2 kubbesi üzerinde hesaplanmasından kaynaklanmaktadır. Mod 3 için voksel model beklenen yapı davranışına daha yakın sonuçlar vermiştir (Şekil 13).

a

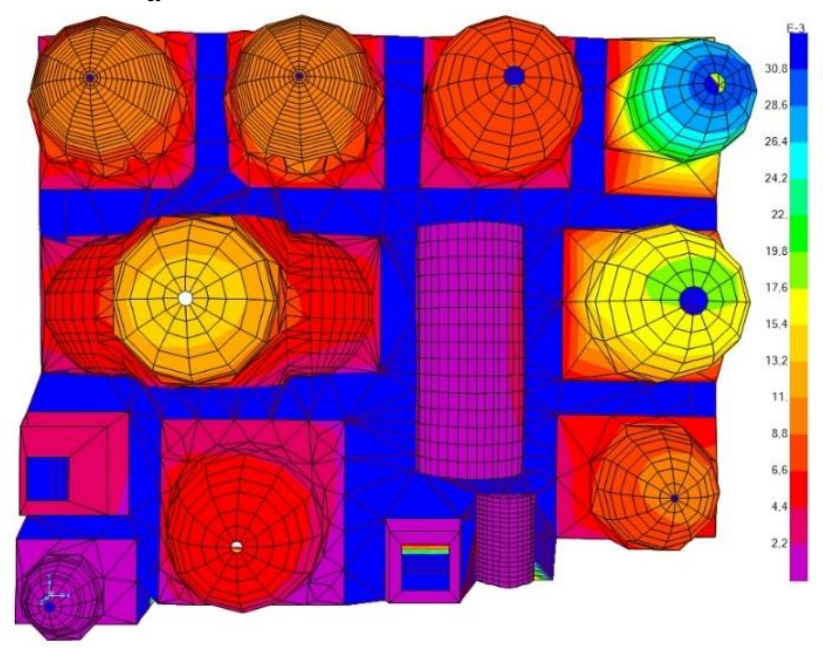

$\mathrm{b}$

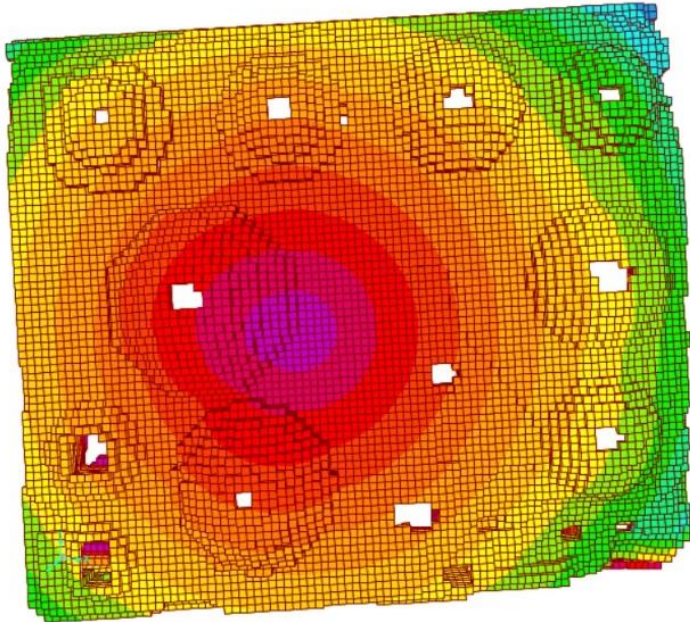

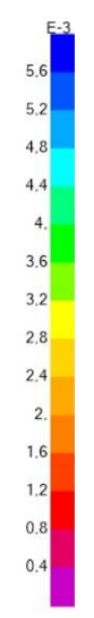

Şekil 13. (a) Klasik model 3.mod (min. $0 \mathrm{~m} / \mathrm{maks} .0 .031 \mathrm{~m})(\mathbf{b})$ Voksel model 3.mod $(\mathrm{min} .0 \mathrm{~m} / \mathrm{maks} .0 .005 \mathrm{~m})$

Modal analiz sonucunda hesaplanan modal kütle katılım oranları Tablo 1'de verilmiştir.

Tablo 1: Modal analiz kütle katılım oranları (\%)

\begin{tabular}{lcccc}
\hline Yön & \multicolumn{2}{c}{ Klasik model kütle katılım oranı (\%) } & \multicolumn{2}{c}{ Voksel model kütle katılım oranı(\%) } \\
\hline Analiz & Statik & Dinamik & Statik & Dinamik \\
UX & 97,75 & 81,71 & 99,61 & 88,64 \\
UY & 97,10 & 79,11 & 99,63 & 88,18 \\
UZ & 81,04 & 54,18 & 99,16 & 87,73 \\
\hline
\end{tabular}

Yapının zati ağırlığı ve hareketli yüklerin etkisi ile düşey taşıyıcılarını teşkil eden beden duvarlarında oluşan eksenel gerilmeler ile kubbe ve tonozlarda oluşan gerilmeler klasik model için Şekil 14a'da, voksel model için ise Şekil 14b'de gösterilmiştir. Gerilme dağılımı her iki modelde paralellik gösterse de özellikle kubbe-duvar geçiş elemanlarında (pandantiflerde) klasik modele ait sonuçlarda gerilme yığılımlarının daha fazla oluştuğu görülmüştür. Klasik modelde E3 kubbesi pandantiflerinde oluşan eksenel gerileme değeri 0,29 MPa iken aynı bölge için voksel modelde oluşan eksene gerile 0,21 MPa'dır. Yapı modellemesine genel olarak bakıldığında klasik modelde pandantif ve duvarlarda oluşan gerilmeler 0,07-0,16 MPa aralığında iken 0,02-0,11 MPa 
arasında oluşmaktadır. Bu durum her iki modelin gerilme renk ölçeğinde de görülmektedir. Ortalama gerilme klasik modele göre voksel modelde $\% 60$ daha düşüktür.

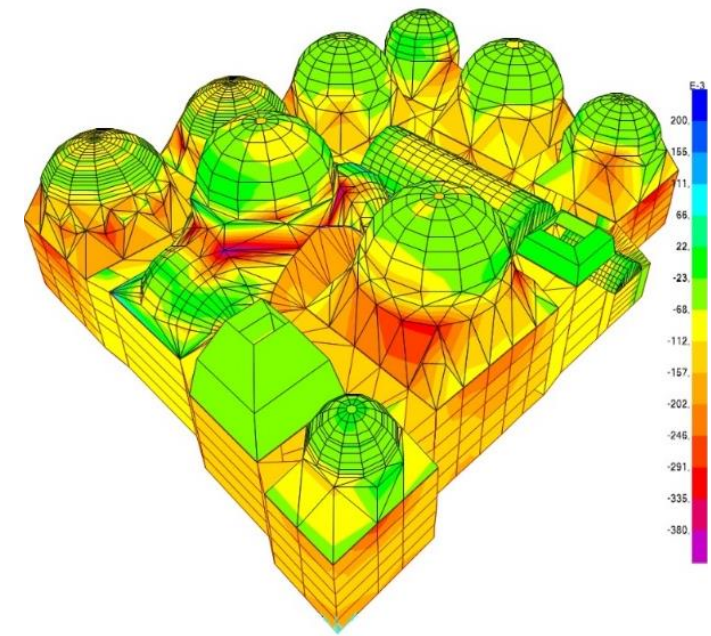

b

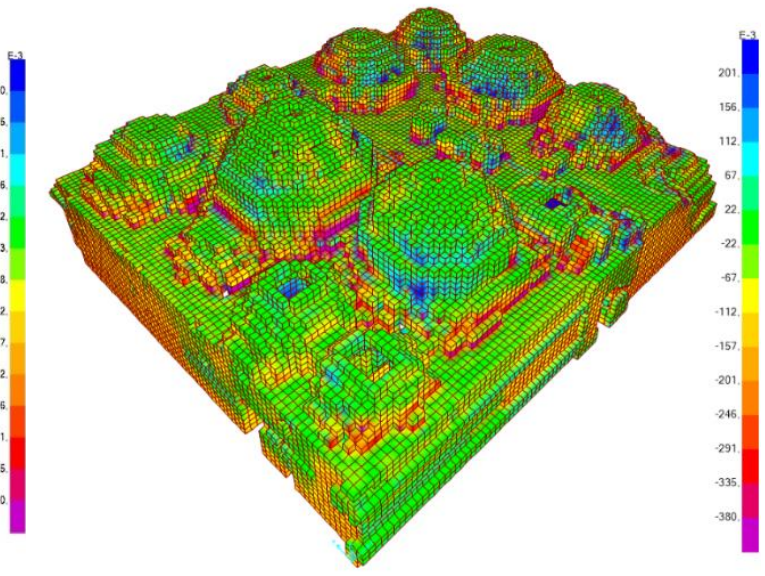

Şekil 14. (a)Klasik model (b)Voksel model G+Q yüklemesi eksenel gerilmeler (MPa)

$\mathrm{X}$ yönündeki deprem etkisi altında, $\mathrm{G}+\mathrm{Q}+\mathrm{Ex}$ yüklemesi, analiz sonucunda yapı elemanlarında oluşan kayma gerilmesi değerleri klasik model için Şekil15a'da, voksel model için Şekil 15b'de verilmiştir. Oluşan kayma gerilmeleri klasik modelde maksimum 0,59 MPa iken voksel modelde 1.01 MPa olarak hesaplanmıştır. Klasik model için X yönü deprem etkisinde hesaplanan kayma gerilmesi değeri voksel modele oranla \%41 daha düşüktür.

a

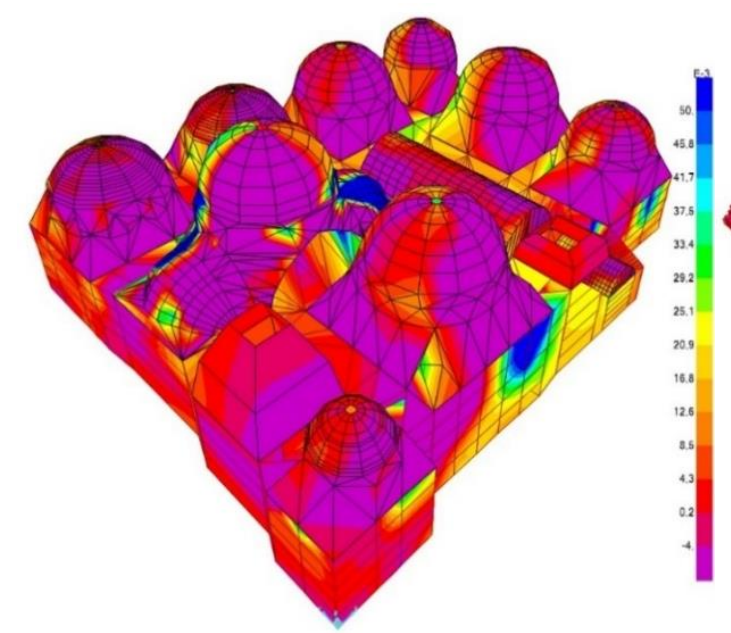

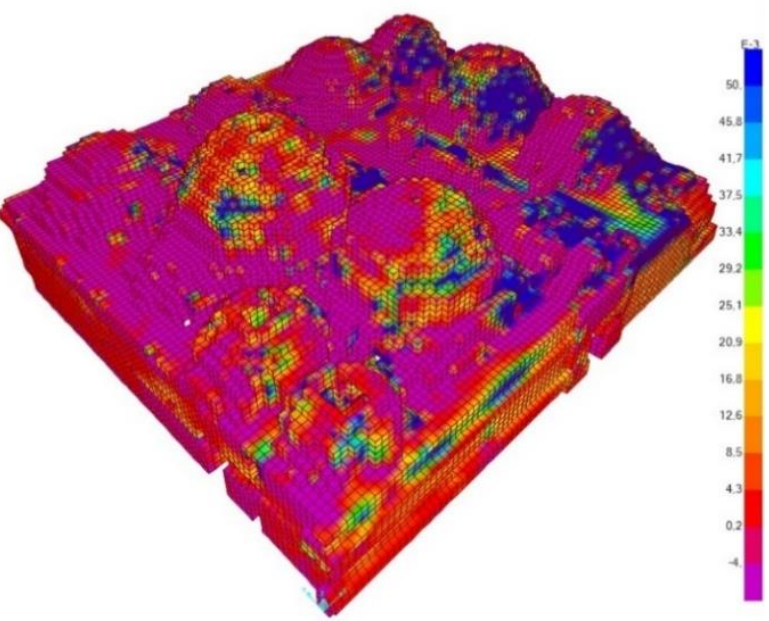

Şekil 15. (a)Klasik model (b)Voksel model G+0.6Q+EX yüklemesi kayma gerilmeleri (MPa)

Y yönündeki deprem etkisi altında, $\mathrm{G}+\mathrm{Q}+$ Ey yüklemesi, analiz sonucunda yapı elemanlarında oluşan kayma gerilmesi değerleri klasik model için Şekil 16a'da, voksel model için Şekil 16b'de verilmiştir. Oluşan kayma gerilmeleri klasik modelde maksimum 0,62 MPa iken voksel modelde 1.04 MPa olarak hesaplanmıştır. Klasik model için X yönü deprem etkisinde hesaplanan kayma gerilmesi değeri voksel modele oranla \%40 daha düşüktür. 

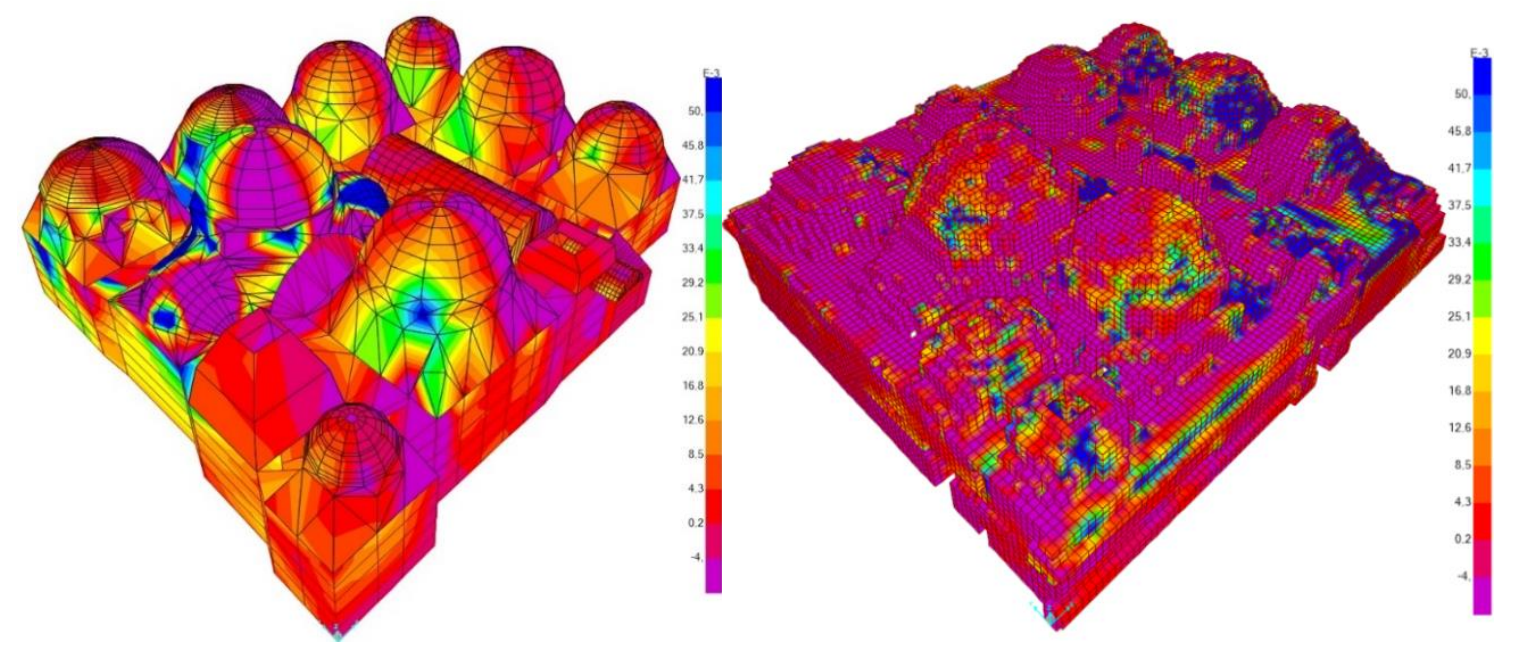

Şekil 16. (a)Klasik model (b)Voksel model G+0.6Q+EY yüklemesi kayma gerilmeleri (MPa)

Taş duvarlar için verilen başlangıç kayma dayanımı değerinin duvar örgüsü, duvar tipolojisi, işçilik ve malzeme kalitesi gibi parametreleri detaylı olarak yansıtmadığ 1 ve ancak fikir verici temsili değerler olarak değerlendirilmesi gerektiği unutulmamalıdır.

Yapı kütlesi incelendiğinde klasik model 2130,0 ton, voksel model 1902,5 ton olarak bulunmuştur. Klasik modelde yapı kütlesi için hesaba dâhil edilen dolgu yüklerinin modele ek üniform yayılı yük olarak girilmiştir. Voksel modelde böyle bir uygulama olmakla birlikte dolgu alanları üç boyutlu olarak yapı geometrisi oluşturulurken belirlenmekte ve yapı modeline dâhil edilmektedir. Bu nedenle yapı ağırlı̆̆ı ve yükleri mevcut yapı ve yüklere daha yakındır.

İki farklı teknikle üretilmiş yapı modelleri karşılaştırıldığında, klasik yapı elemanlarından oluşan modelin ilk üç periyodu 0,0860,081-0,078 sn. mertebesinde iken, voksel tekniği ile üretilen modelin ilk üç modunun 1,623-1,507-1,297 sn. mertebesinde oluşmuştur. Klasik model, voksel modele göre daha rijit davranış göstermiştir.

Klasik model, katı duvarlara mesnetlenmiş farklı kalınlıklardaki plak elemanlardan oluşmaktadır. Voksel model tüm elemanlarının katı eleman olarak modellenmesiyle oluşturulmuştur. Bu sebeple klasik modelde belirleyici unsur plak elamanlardan oluşan kubbelerdir. Voksel model elemanları arasında tam uyum söz konusu olduğundan yapının tüm geometrisi modları belirlemektedir. Yapı modlarına ait toplam yer değiştirme grafikleri incelendiğinde klasik modelde oluşan modal yer değiştirmelerin kubbelerle sınırlı kaldığı tüm yapıyı etkilemediği görülmüştür. Voksel modelde oluşan yer değiştirmelerinde yapının tümünün davranışa katıldığı görülmüştür.

Modal analizlerinde gerekli kütle katılım oranlarının sağlanabilmesi için klasik modelde dinamik analizde 60 adet mod çözümü yapılarak kütle katılım oranları \%81 mertebesine getirilirken, voksel modelde ilk 20 modda kütle katılım oranını \%88'e ulaştığı görülmüştür.

\section{Sonuçlar}

Klasik modelde, yapı elamanlarının tanımlanabilmesi için, rölöve çizimlerinden yararlanılarak duvar, kubbe, tonoz gibi taşıyıcı elemanlardan sistem model oluşturulmuştur. Voksel modelde, nokta bulutu verileri kullanılarak tüm yapı, istenilen boyutta küp birim elemanlarla oluşturulmuştur. Bu nedenle, voksel modellemede rölöve çizimlerine ihtiyaç yoktur.

Klasik modelde, yapı davranışı ve elemanlarının tanımlanması mühendislik yorumuna açıktır. Voksel modelde tüm yapı tek bir kütle olarak davranışa katılmaktadır. Bu nedenle mevcut yığma yapının gerçek davranışına daha yakın sonuçlar sunduğu düşünülebilir.

Klasik modelde yapı kemer, tonoz ve kubbeleri, kalınlıkları sabit elemanlarla oluşturulur. Voksel model en kesit kalınlığı değişken elemanların tanımlanabilmesi daha kolaydır. Bu sebepten dolayı elde edilen gerilme değerlerinin aynı bölgeler için klasik modelde voksel modele oranla daha yüksek gerilmeler oluşturduğu görülmüştür.

Mevcut yapıdaki kubbe ve tonoz gibi eğrisel yüzeye sahip elemanların ana yapıya bağlantısını sağlayan geçiş elemanları, voksel modelde gerçek boyut ve kütlesi ile tanımlanabilmektedir. Bu nedenle, bu geçiş elemanlarının yapıya ve kubbeye bağlantıları gerçeğe daha yakın modellenebilmektedir.

Klasik model ve voksel model ortalama gerilme dağılımları benzerlik göstermekle birlikte, gerilme değerlerinde farklılıklar mevcuttur. Klasik modelde maksimum eksenel gerilmeler voksel modele oranla \%60 düşük çıkmıştır. Klasik modelde maksimum kayma gerilmeleri voksel modele oranla \%40 düşük çıkmıştır. Klasik modelde gerilme yığılımları voksel modele oranla daha 
fazladır. Bunun sebebi, klasik modeldeki eleman tanımlamaları ve birleşimleridir. Voksel model eleman bazında çözümleme olmadığı için daha üniform gerilme dağılımı göstermektedir.

Klasik modelde, yapı modlarını tanımlamada kubbeler etkin iken voksel modelde tüm yapı geometrisi modları tanımlar. Bu sebeple klasik model voksel modele oranla 3 kat daha fazla modlu çözüm gerektirir. Klasik modelde yapı periyotları voksel modele göre \%94 daha kısadır. Klasik modelde ilk üç mod için yer değiştirmeler voksel modele göre ortalama 9-10 kat daha fazladır.

Yapılacak modellemelerde, yapı davranışında önemli görülen bölgelerin, model küp boyutlarının değiştirilerek daha ayrıntılı sonuçlar elde edilmesi mümkün olabilir.

Tarihi yapı modellemelerde yapının gerçek davranışına yaklaşabilmek için yapı malzemeleri ve birleşim elemanlarının mekanik özelliklerinin analizine önem verilmelidir.

\section{Referanslar}

Alicandro, M. (2017). Optimization and Automation of The Post-Processing High Resolution UAV Photogrammetric Data. Ricerche di Geomatica, 25-34.

Asır Poje Arşivi (2017). Edirne - Merkez Gāzi Mihâl Bey Hamamı Sanat Tarihi Raporu. T.C. BAŞBAKANLIK VAKIFLAR GENEL MÜDÜRLÜĞÜ,Edirne Vakıflar Bölge Müdürlüğü, EDİRNE.

Cardani, G., \& Angjeliu, G. (2016). Challenges from building information modeling to finite element analysis of existing buildings. Structural Analysis of Historical Constructions Anamnesis,diagnosis, therapy,controls (s. 120-124). içinde London: Taylor\&Francis Group.

Castellazzi, G., D’Altri, A. M., Bitelli, G., Selvaggi, I., \& Lambertini , A. (2015). From laser scanning to finite element analysis of complex buildings by using a semi-automatic procedure. sensors. http://amsacta.unibo.it/4246/1/Castellazzi_sensors87308 submitted.pdf adresinden alınd 1

Castellazzi, G., D’Altri, A. M., Miranda, S., Ubertini, F., Bitelli, G., Lambertini, A., . . . Tralli, A. (2016, 06 5-10). A Mesh Generation Method For Historical Monumental Buildings: An Innovative Approach. Ferrara, Italy: ECCOMAS Congress 2016 VII European Congress on Computational Methods in Applied Sciences and Engineering.

Castellazzi, G., D'Altri, A. M., Miranda, S. d., \& Ubertini, F. (2016). An innovative numerical modeling strategy for the structural analysis of historical monumental buildings. Engineering Structures.

DBYBHY. (2007). Deprem Bölgelerinde Yapılacak Binalar Hakkında Yönetmelik. Ankara: Bayındırlık ve İskan Bakanlığı.

Giordano, A., Mele, E., \& De Luca, A. (2002, 01 28). Modelling of historical masonry structures: comparison of different approaches through a case study. Engineering Structures 24 (2002) 1057-1069.

Magenes, G., \& Penna, P. (2009). Existing Masonry Buildings: General Code Issues And Methods Of Analysis And Assessment. Eurocode 8 Perspectives from the Italian Standpoint Workshop, (s. 185-198). Napoli, Italy.

Manich, C. G., Kelman, T., Coutts, F., Qiu, P., Murray, P., Longo, C. G., \& Marshall, S. (2016). Exploring the use of image processing to survey and quantitatively assess historic buildings. Structural Analysis of Historical Constructions Anamnesis,diagnosis, therapy,controls (s. 125-132). içinde London: Taylor\&Francis Group.

Roca, P., Cervera, M., Gariup, G., \& Pela, L. (2010). Structural Analysis of Masonry Historical Constructions. Classical And Advanced Approaches. Arch Comput Mehods Eng, 299-325. 